\title{
Comparative study on non descent vaginal hysterectomy verses abdominal hysterectomy for benign uterine conditions
}

\author{
Chandrakar $K^{1}$, Singh $\mathbf{N}^{2}$, Charla $S^{3}$ \\ ${ }^{1}$ Dr Kshma Chandrakar, Assistant Professor, ${ }^{2}$ Dr Neelam Singh, Associate Professor, ${ }^{3}$ Dr Surekha Charla, Senior \\ Resident, L. N. Medical College \& J. K. Hospital, Kolar Road, Bhopal, MP, India.
}

Address for Correspondence: Dr Kshma Chandrakar, Assistant Professor, L.N. Medical College \& J.K. Hospital, Kolar Road, Bhopal.

\begin{abstract}
Objectives: To determine superiority, safety and effectiveness of vaginal over abdominal route of hysterectomy and to show that vaginal hysterectomy requires shorter duration of surgery, less blood loss, early post operative recovery with early ambulation of the patient, less operative complication \& less duration of hospital stay compared to total abdominal hysterectomy. Methodology: A prospective comparative study conducted among 150 women undergoing hysterectomy for benign uterine condition. Those undergoing non descent vaginal hysterectomy were compared with those undergoing total abdominal hysterectomy. Results: When we compared NDVH with TAH it was found that it takes less time

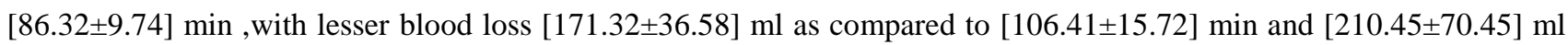
in abdominal hysterectomy. The pain scores and hospital stay is also favorable in vaginal route. Conclusion: From our study we conclude that a scar less surgery in the form of NDVH should be preferred by all surgeons as the primary route of perform hysterectomy. Previously considered contraindications for NDVH have now been ruled out.
\end{abstract}

Key words: Non Descent Vaginal Hysterectomy, Total Abdominal Hysterectomy, Hospital stay, Pain scores.

\section{Introduction}

The uterus is a hormone responsive reproductive organ that supports the Bladder and the Bowel. It has essential functions throughout a woman's life. Hysterectomy being the surgical removal of all or a part of the uterus is the most common surgery performed by the gynecologists, next only to caesarean section. Although enormous advances have occurred in the medical management of a number of conditions, hysterectomy continues to have a place in its definitiveness $[1,2]$.

The past few years have seen growing indications for vaginal hysterectomy which is now preferred over abdominal hysterectomy. "REDISCOVERY" of the vaginal route, the term rediscovery is justified by the fact that vaginal hysterectomy is a technique that had already been introduced and performed centuries age, but with little success among gynecologist. Probably because of inexperience or lack of enthusiasm among

Manuscript received $28^{\text {th }}$ October 2016

Reviewed: $10^{\text {th }}$ November 2016

Author Corrected: $24^{\text {th }}$ November 2016

Accepted for Publication 6 ${ }^{\text {th }}$ December 2016 gynecologists, who preferred the abdominal route, believing it to be a safer and easier procedure? In the recent decade increased expertise has been achieved by the gynecologists and better compliance has been reported by patients [3].

Vaginal hysterectomy is minimal bowel hysterectomy. The morbidity associated with abdominal incisions viz, infection, dehiscence, evisceration, discomfort or hernia and above all a scar are avoided. In vaginal hysterectomy, there is decreased post op morbidity and early ambulation.

Prolonged necessary care is reduces. Bowel functions return earlier and hence parenteral fluid therapy can be minimized. Fewer post op adhesions are likely to develop after vaginal hysterectomy. In case of extreme obesity, vaginal hysterectomy has a distinct advantage over the abdominal method. Vaginal hysterectomy is better tolerated by elderly patients and those with complicated medical disease [3]. 
It is said that the two are not competitive procedures but each has recommends that the choice of approach should be based on the surgical indication, patient's anatomic condition, data supporting the approach, informed patient preference, and the surgeon's expertise and training.

As seen in most hospitals, here also in $\mathrm{J}$ K Hospital, TAH was more popular than NDVH. But with the introduction of LAVH where majority of the procedure is accomplished vaginally, there developed a growing in NDVH also. Hence, the present study is to show that $\mathrm{NDVH}$ involves less morbidity, is less invasive, requires less hospitalization, has a faster recovery time and has many more advantages when compared to TAH. Hence it should be the gynecological surgeons's first choice wherever feasible.

\section{Methodology}

A prospective comparative study conducted among women hysterectomy for benign uterine condition. Those undergoing non descent vaginal hysterectomy were compared with those undergoing total abdominal hysterectomy from January 2015 to June 2016 (18 months). The study was conducted in J K Hospital \& Research Centre, Bhopal which is a 750 bedded multidisciplinary tertiary and referral hospital in Bhopal.

The women in OPD were screened and those requiring hysterectomy for various indications were taken for the study. Annually, around 300-350 hysterectomies are performed in our hospital. Of these around $2 / 3^{\text {rd }}$ are being performed via abdominal route and only $1 / 3^{\text {rd }}$ by vaginal route.

\section{Inclusion criteria}

1. Uterine size up to 12 weeks gestation

2. Non prolapsed uterus

\section{Exclusion criteria}

1. Uterine size more than 12 weeks.

2. Complex ovarian cyst (or $>8 \mathrm{~cm}$ ).

3. Any degree of uterine descent.

4. Restricted mobility of uterus.

5. Suspicion of genital malignancy.

6. Any existing significant bleeding diathesis.
Sample Size- Total of 150 patients.

Group A: 75 patients undergoing vaginal hysterectomy

Group B: 75 patients undergoing abdominal hysterectomy

Approved proforma were used for collecting demographic data, clinical data, preoperative evaluation, intra-operative observations and post-op findings and complications.

Written informed consent was taken from patient relatives for surgical procedure and regarding the potential risks of anesthesia and surgery and also post operative evaluation.

All cases were given Inj. Voveron (diclofenac sodium $75 \mathrm{mg}$ ) I.M. just before leaving the theatre and the same was repeated 8 hourly for the next 48 hrs.

\section{The main parameters used for comparison were-}

1) Intra-operative blood loss-blood loss was calculated by noting the weight of mops and blood collected in suction apparatus

2) Time taken for surgery

3) Intraoperative injury- Any injury to Bowel, Bladder or Ureter was noted.

4) Pain scoring according to visual analog scale was done [4]

5) Length of hospital stay

Statistical Analysis- Statistical analysis was done by using SPSS software version 16. The data collected in the present study were presented in the form of tables and graphs.

The data were analyzed statistically by calculating the descriptive statistics viz,. Mean SD, percentage and 95\% confidence interval for all continuous variables.

The difference in mean is tested using independent sample students ' $\mathrm{t}$ ' test and the measures of association between the qualitative variables are assessed using chi square tests. The inference is considered statistically significant if $\mathrm{p}<0.05$.

\section{Observations}

Most of the women in the group A were of 46-50 years (40\%) Most of the women in the group B were of 41-55 years $(42.66 \%)$ The association between age and route of surgery was not significant. 
Table-1: Mean time taken during surgery.

\begin{tabular}{|c|c|c|c|c|c|}
\hline \multirow{2}{*}{ Factors } & Type of surgery & Mean \pm SD & $\begin{array}{c}\text { 't' Unpaired } \\
\text { Value }\end{array}$ & DF & 'P' Value \\
\cline { 1 - 3 } Time & NDVH & $86.32 \pm 974$ & 15.39 & 148 & 0.0001 HS \\
\cline { 2 - 3 } & TAH & $106.41 \pm 15.72$ & & \\
\hline
\end{tabular}

The difference in time noted was highly significant statistically

Table 2: Mean blood loss during surgery.

\begin{tabular}{|c|c|c|c|c|c|}
\hline \multirow{2}{*}{ Factors } & Type of surgery & Mean \pm SD & $\begin{array}{c}\text { 't' Unpaired } \\
\text { Value }\end{array}$ & DF & 'P' Value \\
\cline { 1 - 4 } Blood loos & NDVH & $171.32 \pm 36.58$ & 7.16 & 148 & 0.0001 HS \\
\cline { 2 - 3 } & TAH & $210 \pm 70.56$ & & \\
\hline
\end{tabular}

The blood loss between the two groups were compared and the $\mathrm{P}$ value obtained was 0.0001 which was highly significant. More blood loss was observed in TAH group. As TAH requires entry via skin, abdominal fat, rectus and muscle, hence blood loss was more.

Table-3: Mean pain scoring.

\begin{tabular}{|c|c|c|c|c|c|}
\hline Factors & Type of surgery & Mean \pm SD & 't' Unpaired Value & DF & 'P' Value \\
\hline \multirow{2}{*}{ Pain score } & TAH & $5.04 \pm 1.12$ & 6.27 & 148 & $0.0001 \mathrm{HS}$ \\
\cline { 2 - 4 } & NDVH & $4.32 \pm 1.03$ & & & \\
\hline
\end{tabular}

* Pain scoring on postoperative day-3 in the VAS Mean pain score in NDVH was 4.3 and Mean pain score in TAH was $5.04 \mathrm{~cm}$

* The difference in the pain rating score between the two groups was found to be statistically highly significant with a $\mathrm{P}$ value 0.0001 .

* Post op pain was much less in NDVH cases hence Post operative mobilization and ambulation was earlier in NDVH patients.

Table 4: Mean hospital stay.

\begin{tabular}{|c|c|c|c|c|c|}
\hline Factors & Type of surgery & Mean \pm SD & 't' Unpaired Value & DF & 'P' Value \\
\hline \multirow{2}{*}{ Hospital stay } & TAH & $6.27 \pm 2.36$ & 4.28 & 148 & $0.0001 \mathrm{HS}$ \\
\cline { 2 - 3 } & $\mathrm{NDVH}$ & $5.44 \pm 1.43$ & & & \\
\hline
\end{tabular}

* Mean duration of hospital stay in NDVH 5.44 days

* Mean duration of hospital stay in TAH 6.27 days

* The difference in the duration of hospital stay when the two groups were compared was found to be statistically significant with a $\mathrm{P}$ value 0.00001 .

* The cause of prolonged hospital stay was mostly due to prolonged catheterization or due to post op complications requiring observation and monitoring.

\section{Discussion}

Hysterectomy is a major gynaecological surgery and is often easiest when least necessary. The uterus is a priced possession of every female. Hence the indication for hysterectomy in any cases must therefore be clearly defined, and should be one for which more conservative treatment is not likely to be efficacious.

Nowadays a spectrum of approaches is available for performing hysterectomy. Traditional vaginal and abdominal hysterectomies represent the least and most invasive techniques respectively, whereas the laproscopic procedures remain 
in the middle of the spectrum. Too often, a route is chosen merely because it has become a routine procedure in that particular institution or clinic. The ease and convenience offered by a large abdominal incision have led to the preponderance of abdominal hysterectomy over the other types of hysterectomy, and a rational evidence based approach should be followed for the selection of a right type and route of hysterectomy.

In our study most of patients were in the age group of 40-49 years, which was well compared with the study carried out by Dewan Rupali et al [5] and also in other studies as shown below.

With respect to size of the uterus and delivery of the uterus, we had difficulty in delivery of uterus in few patients which was accomplished by morcellation and or enucleation of leiomyoma. Kumar et al [6] successfully carried out vaginal hysterectomies in 95\% (76/80) and 60 of their patients needed morcellation or hemisection or myomectomy and they considered vaginal hysterectomy safe up to 12 week size. According to Sheth SS [7] the preoperative sonographic estimation of uterine volume and the findings at examination under anesthesia help in choosing the vaginal route. They needed debulking for uteri with a volume of more than $300 \mathrm{~cm}^{3}$. Regarding dubulking measures, various techniques were used for easy removal of uterus in NDVH group. In our study, in NDVH group, Bisection was carried out in 12 (16\%) cases, morcellation in 2 cases $(2.67 \%)$. No specific technique was employed in 59 cases $(78.67 \%)$.

Entire removal of uterus was done in all cases of TAH without using any specific debulking method. The safety of the technique has already been tested by various surgeons. Magoe et al [8], in his series removed large uteri weighing more than 1000 gms vaginally.Aparna Hegde et al [9], could successfully remove uteri size up to 16 weeks using these techniques. D Kammerer Doak and J Mao[10], concluded through their study that uterine morcellation at the time of vaginal hysterectomy is safe and facilitates the vaginal removal of moderately enlarged and well supported uteri without increasing peri operative morbidity. S.Taylor et al [11], compared TAH with vaginal hysterectomy with morcellation. Uterine weights up to $982 \mathrm{gm}$ were included in the study. They found that uterine morcellation at the time of VH is safe facilitating the removal of moderately enlarged uteri and is associated with decreased hospital stay and post operative morbidity compared to the abdominal route. Mazdisnian F et al [12] could remove uteri up to 1000 gm1s vaginally using these techniques. Similarly Unger JB [13] could remove uteri weighing up to 700 gms using these techniques.

Time Taken Regarding Time taken for surgery, In NDVH group duration was between 66 mins to 120 mins. The increase in time taken for surgery was mainly due to the de-bulking procedures.

\begin{tabular}{|c|c|c|}
\hline Study by & NDVH Time in Min. & TAH Time in Min. \\
\hline Garg et al [15] & 41.2 & 62 \\
\hline Tariq Misky and A Magos [16] & 68.80 & 101.0 \\
\hline S Bharatnur et al[17] & 65 & - \\
\hline Shailesh Kore et al[9] & 42.5 & 82.3 \\
\hline Abhinandan Sawakar [18] & 84.3 & 106.4 \\
\hline Present study & 86.3 & . \\
\hline
\end{tabular}

Mean duration of surgery in NDVH group was 86.3 minutes and mean duration of surgery in TAH group was 106.4 minutes. Similar results were seen in other studies $[9,15,17]$. Duration of surgery was more in cases which required either debulking or in cases who had a history of previous on LSCS.

Mean blood loss in NDVH group was $171.32 \mathrm{ml}$ and mean blood loss in the TAH group was $210.45 \mathrm{ml}$. the blood losses between the two groups were compared and the $\mathrm{p}$ value obtained was 0.0001 , which was statistically significant. In the clinical analysis done by Pradeep Kumar Garg et al [15] mean blood loss in the NDVH group was 286 ml whereas that in the TAH group was $310 \mathrm{ml}$.

Here also the difference in the blood loss between the two groups was not statistically significant. Dewan Rupali et al [5], in their study found that mean blood loss for NDVH group was $290 \mathrm{ml}$. Singh Abha et al [16], in their study showed that the blood loss was statistically significant with $\mathrm{p}$ value 0.001 . 
Pain Scoring on VAS (visual analogue scale): Regarding the pain scoring on postoperative day-3 in the VAS, mean pain score in NDVH group was 1.32. Mean pain score in TAH group was 5.04. The difference in the pain rating scoring between the two groups was found to be statistically with a value $<0.0001$. Postoperative mobilization was earlier in group A patients. This Study proved that post operative patient comfort was very much increased with NDVH. This is the one of the most important advantage of NDVH over TAH. This was proved by studies conducted by Pradeep Kumar Garg et al [15], S. Taylor et al [12] as well as Dewan Rupali et al [5].

\section{Hospital Stay.}

\begin{tabular}{|c|c|c|}
\hline Study by & NDVH & TAH \\
\hline Abhinandan Sawakar [18] & 7.9 & 9.92 \\
\hline S. Taylor et al [12] & 2.6 & 3.9 \\
\hline Tariq Misky and A Magos [17] & 3.6 & 5 \\
\hline Pradeep Kumar Garg et al [15] & 1.2 & 4.3 \\
\hline Singh Abha et al [16] & 3.54 & 8.18 \\
\hline Present study & 5.44 & 6.27 \\
\hline
\end{tabular}

The difference in the duration of hospital stay when the two group were compared was found to be statistically significant with a $\mathrm{p}$ value of 0.0001 . Length of hospital stay was significantly decreased with NDVH group ( $<<0.001$ ) compared to TAH group in the study conducted by various authors $[5,9,10,12,15,16]$.

Then the two groups were compared regarding intraoperative injury, postoperative bleeding needing laparotomy and post operative blood transfusion. Chi Square test was applied for statistical analysis. There was however no statistically significant difference between the two group regarding post operative blood transfusion with $\mathrm{p}$ value of 0.47. Similar conclusion was derived by Pradeep Kumar Garg et al [15] as well as Mazdisnian F et al[13] and S. Taylor et al [12] through their studies.

New developments such as fibre optic light source, longer instruments for obese patients etc combined with existing methods of uterine morecellation may now allow many larger uteri to be removed vaginally. A critical evaluation of the methods is required to identify an optimum place for every type of hysterectomy and to enable the gynecologist select the right method for a particular patient to bring about the best possible outcome.

\section{Conclusion}

From our study we conclude that a scar less surgery in the form of NDVH should be preferred by all surgeons as the primary route of perform hysterectomy. Previously considered contraindications for NDVH have now been ruled out. Less intra-operative blood loss, less febrile morbidity, low postoperative complications, faster recovery, less hospital stay demonstrate that the vaginal route should be the choice of operation for non-descent cases.

Vaginal hysterectomy is least invasive route, safe and effective procedure for benign non-prolapsed cases. Besides the faster recovery and lower incidence of bleeding and other complications, vaginal route lowers cost for health systems.

Funding: Nil, Conflict of interest: None initiated, Permission from IRB: Yes

\section{References}

1. Drellich MG, Bieber I. The psychologic importance of the uterus and its functions: some psychoanalytic implications of hysterectomy. The Journal of nervous and mental disease. 1958 Apr 1;126(4):322-36.

2. Sheth SS. Vaginal hysterectomy. In: Puri R, Malohatra N. eds. Operative obstetrics and Gynaecology. New Delhi. Jaypee brother's medical publisher. 2009:499-510.

3. Goel N, Rajaram S, Ghumman S.eds. Step by Step Non-Descent vaginal hysterectomy. $2^{\text {nd }}$ edtion, New Delhi. Japee brothers medical publishers; 2010:42-62.

4. Huskisson EC. Visual analogue scales. Pain measurement and assessment. 1983:33-7. 
5. Dewan Rupali, Agarwal Suivani, Manisha, Minocha Bharti, Sen Soumendra K, Non-descent vaginal hysterectomy - An experience, J. Obstet. Gynecol. Ind. Vol. 54, No.4, July/Aug. 2004, Pg.376-378.

6. Kumar Sushil, Antony ZK, Vaginal hysterectomy for benign nonprolapsed uterus. Intial Experience. J. Obstet. Gynaecol. Ind. Vol. 54; No. 1. January /February 2004; Page. 60-63.

7. Sheth SS. The scope of vaginal hysterectomy. European Journal of Obstetrics \& Gynecology and Reproductive Biology. 2004 Aug 10;115(2):224-30.

8. Magos A, Boyiras N, Sinha R, Richardson R, Vaginal hysterectomy for the large uterus. British Journal of Obstetrics and Gynecology, 1996;103:246.

9. Shailesh Kore, Anjali Sah, Aparna Hedge. Bisection, myomectomy and coring in vaginal hysterectomy of large uterus. Dept. of Obstetics and Gynaecology, LTMMC and LTMG Hospital, Sion, Mumbai: bhj oct 1999:4104;706.

10. Doucette RC, Sharp HT, Alder SC, Challenging generally accepted contraindication to vaginal hysterectomy. Am J Obstet Gynecol 2001;184:1386-9; discussion 1390-1.

11. Kammerer-Doak D, Mao J. Vaginal hysterectomy with and without morcellation: the University of New Mexico hospital's experience. Obstet Gynecol. 1996 Oct; 88(4 Pt 1):560-3.

12. Taylor S, Romero A, Qualls C, Rogers R. Abdominal hysterectomy for the enlarged myomatous uterus compared with vaginal hysterectomy with morcellation. The American Journal of Obstetricians and Gynecologist. 1996;162:994-998.
13. Mazdisnian F, Kurzel RB, Coe S, Bosuk M, Montz F. Vaginal hysterectomy by uterine morcellation: an efficient, non-morbid procedure. Obstet Gynecol. 1995 Jul; 86(1):60-4.

14. Unger JB. Vaginal hysterectomy for the woman with a moderately enlarged uterus weighing 200 to 700 grams. Am J Obstet Gynecol. 1999 Jun;180 (6 Pt 1) : 1337-44.

15. Pradeep Kumar Garg, D Deka, Neena Malhotra. Non-descent vaginal hysterectomy for Benign Condition. A better proposition than abdominal hysterectomy. Obst. \& Gynaec. June 2002. Today. Vol VII, No. 6.

16. Dr. Abha Singh, Shweta Bansal, Vaginal hysterectomy for non prolapsed uterus. J Obstet Gynaecol India Vol 56, No 2: March/April 2006; 152-55.

17. Tariq Miskry and Adam Magos, Randomized prospective double-blind comparison of abdominal versus hysterectomy in women without utero vaginal prolapsed. Acta Obstetrics and Gynecology 2003; 82:351-358.

18. Sawkar, Abhinandan Kumar H, Vaginal hysterectomy vs total abdominal hysterectomy in non descent uterus-a comparative study, D space at RGUHS, Karnataka, Bangalore, Apr-2009;22-80.

19. Liu Sui Ling, LI Xiao Mao, Clinical analysis of transvaginal hysterectomy in 50 cases with uterine myoma. Department of Obstetrics and Gynaecology. Third Affiliated Hospital. Sun Vat Sen University, China. Chinese Journal of Clinical Obstetrics and Gynecology;2005:02. Am J Obstet Gynecol 2001; 184: 1386-9; discussion 1390-1.

\section{How to cite this article?}

Chandrakar K, Singh N, Charla S. Comparative study on non descent vaginal hysterectomy verses abdominal hysterectomy for benign uterine conditions. Int J Med Res Rev 2016;4(11):2071-2076.doi:10.17511 /ijmrr. 2016.111 .29$. 